Original Article

\title{
KNOWLEDGE AND ATTITUDE REGARDING EYE DONATION AMONG THE ADOLESCENTS : A CO-RELATIONAL STUDY
}

\author{
Heyke M. Chacko ${ }^{1}$, Jasmine Mathew ${ }^{1}$, Jidiya Jose ${ }^{1}$, Jisha Dominic ${ }^{1}$, Sachina B.T. ${ }^{2} \&$ Babu D. ${ }^{3}$ \\ ${ }^{1}$ Students P.B.B.Sc (N), ${ }^{2}$ Lecturer, ${ }^{3} \mathrm{HOD} \&$ Associate Professor, Department of Medical Surgical Nursing, Yenepoya \\ Nursing College, Yenepoya University, Mangalore , Karnataka, INDIA.

\section{Correspondence:} \\ Sachina B.T., \\ Lecturer, Department of Medical Surgical Nursing, Yenepoya Nursing College, M angalore, Karnataka, India. \\ E-mail: sachinbanur@gmail.com
}

\section{Abstract :}

Background : Vision is the most important sense because it allows interacting freely with the environment and enjoying the beauty of life. The eye is the window to the world and it is a sensitive, highly specialized sense organ subject to various disorders, many of which lead to impaired vision. Blindness is a lack or loss of ability to see; lack of perception of visual stimuli. The diseases of the cornea are one of the major causes of blindness in India for which the vision can be restored by eye donation. Eye sight is very important for human life. The World Health Organization (W.H.O) estimates that for every 5 seconds, someone goes blind. Globally 37 million people are blind and of these nearly 10 lakh blind people are willing for corneal transplantation. Well informed adolescents could be expected to influence eye donation rates.

Methods : Descriptive survey approach with co-relational design was used for the study. The aim of the study was to assess the knowledge and attitude regarding eye donation among the adolescents and to identify the relationship between them. The Structured knowledge questionnaire and Attitude scale on eye donation were used to collect the data. The data were collected by questionnaire method from 100 adolescents, who were selected using non-probability purposive sampling technique at Yenepoya pre- university college, M angalore, India. Data collected from the subjects were analyzed using descriptive and inferential statistics.

Results : The mean percentage of the knowledge scores among adolescents were $57 \%$, the mean percentage of the attitude scores among adolescents were $70.5 \%$ and there was a positive correlation between knowledge and attitude among adolescents $\left(r_{(98)}=0.201\right)$. Table valuer $\left._{(98)}=0.236, p<0.313\right)$.

Conclusion : The findings of the study showed that the adolescents had good knowledge and positive attitude towards eye donation and there was a positive co-relation between knowledge and attitude among adolescents.

Keywords: Knowledge; Attitude; Eye donation; Adolescents.

\section{Introduction :}

Vision is the most important sense because it allows interacting freely with the environment and enjoying the beauty of life. Eye is sometimes called the "mirror of soul," it twinkles with humor, sparkles with joy, softens with worry, hardens with anger, and clouds when things go wrong or one loses hope. The eye often reflects physical

\section{Access this article online Quick Response Code}

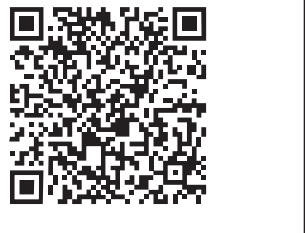

health ${ }^{1}$. The use of sight is an integral part of early life experiences. Most individuals are not consciously aware of the degree to which they depend on it for daily functioning. Once vision becomes significantly limited, it influences the activities of daily living. Even simple tasks become difficult to perform. So eye care is very important to maintain the eye health ${ }^{2}$.

The eye is the window to the world and it is a sensitive, highly specialized sense organ subject to various disorders many of which lead to impaired vision. Blindness is a lack or loss of ability to see; lack of perception of visual stimuli. The disease of the cornea is one of the major causes of blindness in India for which the vision can be restored by eye donation ${ }^{3}$.

Eye donation is an act of donating one's eyes after his/her death. Only corneal blinds can be benefitted through this process not other blinds. It is an act of charity, purely for the benefit of the society and istotally voluntary ${ }^{3}$. 
The problem of blindness all over world is as old as mankind itself. The World Health Organization (W.H.O) estimates that for every 5 seconds, someone goes blind. Globally 37 million people are blind and of these nearly 10 lakh blind people are willing for corneal transplantation. The present annual need of cornea is 75,000 to $1,00,000$ but unfortunately we are receiving 28,000 corneas only. Many deaths took place daily. If people are ready to donate their eyes, we can help many blind people to get their vision ${ }^{3}$.

In India, there are approximately 120 lakh blind in both eyes and 80 lakh blind in one eye, which is about one fourth of the total blind population of the world. This means 14.9 out of every 1000 people in India are blind compared to just 3 per 1000 in the developed countries. Blindness in most cases is avoidable that is, either preventable or curable. Of the 120 lakh blind, approximately 103 lakh are curable by relatively simple operations, unfortunately yet they remain uncured. About 96 lakh persons suffer from cataract which can be cured by a simple operation. Seven lakh of Indian population suffering from corneal blindness, mostly children in their early childhood, can be cured by corneal transplantation. ${ }^{4}$

There is a severe lack of donor eyes in India as only 4,500 corneal operations are being performed every year, while 30,000 new victims are added each year to the long list of 7 lakh patients already waiting to be cured. Although there are enough qualified surgeons and plenty of potential patients, corneal transplantation cannot be carried out due to lack of donor corneas. Eye donation means people pledging to donate their eyes after death to be used for corneal grafting for restoring sight to corneal blind people. In India there are more than 80 lakh deaths every year but sadly the corneal donations do not exceed a few thousand ${ }^{4}$.

Karnataka Statistics of Corneal transplantation showed that 2143 corneal transplantation done in the year 200607, 2280 corneal transplantation done in 2007-08, 2405 corneal transplantation done in 2008-09, 3840corneal transplantation done in 2009-10, 1570 corneal transplantation done in the year 2010-11 (up to October) ${ }^{5}$.
Corneal transplantation is the most successful among all forms of organ transplant procedures. Ironically the impact of shortage of donor eyes is most glaring in the developing conservative Asian countries where corneal disease account for a large proportion of curable blindness. Collection of donor eyes is therefore a priority in any organized effort to alleviate the needless scourge of blindness ${ }^{6}$.

Vision 2020; The Right to Sight, It is the global initiative to reduce avoidable blindness by the year 2020.India is also committed to this initiative ${ }^{7}$.

National center for advancement of rural eye care estimated blindness in India from 2000 through 2020. Results obtained from the estimations are as follow: The number of blind persons in India in $\mathbf{2 0 0 0}$ was estimated to be 18.7 million; the number of blind persons in India would increases to 24.1 million in 2010, and to 31.6 million in $2020^{8}$

A cross-sectional study was conducted to assess the awareness of eye health care and eye donation among1525 secondary level school students of North Kolkata, West Bengal, India. A pre-tested, semi-structured questionnaire was administered to collect data. The findings showed that, 1284 (84.2\%) participants opined that awareness on eye health care can prevent most of the blindness and 1206 (79.1\%) students knew that Vitamin A has important role in prevention of childhood blindness. Majority, 1235 (81.0\%) students were aware of eye donation after death while only 489 (32.1\%) participants knew that the ideal time for eye donation is within 6 hours of death. 802 (52.6\%) participants mentioned printed and electronic media (like newspaper and television) as the major source of information on eye donation. The study concluded that, media publicity to increase awareness of eye donation and eye health care is not enough. Strategies have to be developed to educate the students, so that they can act as motivators for enhancing eye donation and increasing eye health care awareness ${ }^{9}$.

A study was conducted to evaluate the attitudes and 
willingness to donate organs among 68 cornea transplant recipients in America. The results showed that religion was a contributing factor for a negative decision to donate organs. Only $29 \%$ of participants, most of whom were nonreligious, were carrying a signed donation card. Around $58 \%$ of the patients knew that the cornea graft can be derived from a deceased person; most of these patients were of European or American origin. Seventy-three percent knew that donation requires the agreement of a family member. Age, gender, marital status, and education were not significantly associated with attitude towards donation. The study concluded that stronger efforts are needed by transplant coordinators, physicians, and nurses to improve the education and knowledge of patients and their families about the basic aspects of cornea transplantation $^{10}$.

A study was conducted to determine the "awareness of eye donation" and "willingness to pledge eyes for donation" among 7,775 subjects of all ages in the rural population of Andhra Pradesh, southern India. The results showed that age-gender adjusted prevalence of awareness of eye donation in this population was $30.7 \%$ (95\% Cl: $29.5-31.9)$ but only $0.1 \%$ (age-gender adjusted prevalence) $(95 \% \mathrm{Cl}$ : $0.05-0.25$ ) had pledged eyes. On multivariate analysis the awareness of eye donation was significantly less in those subjects $\geqslant$ or $=70$ years old (OR $0.7 ; 95 \% \mathrm{Cl}: 0.6-0.8)$, illiterates (OR 0.2; 95\% Cl: 0.1-0.2), females (OR 0.8; 95\% Cl: 0.7-0.9), lower socioeconomic status group (OR 0.4; 95\% $\mathrm{Cl}$ : 0.4-0.5) and Christians (OR 0.2; 95\% Cl: 0.1-0.6). Media comprised the major source of information about eye donation. Of those aware of eye donation, $32.9 \%$ were willing to pledge eyes, and $50.6 \%$ needed more information to decide whether or not to pledge their eyes. The study concluded that there needs to be more transfer of knowledge if more eyes are to be pledged. One-third of those aware of eye donation have not pledged their eyes, and an additional $50.6 \%$ needed more information to decide ${ }^{11}$.

Materials and Methods :

A descriptive survey approach with co-relational design found to be appropriate and selected for this study. After obtaining ethical committee approval and formal permission from the concerned authority, the data were collected from 100 adolescents. A non-probability purposive sampling technique was used to select the subjects and written informed consent was obtained from them. The data were collected using Demographic Proforma, Structured Knowledge Questionnaire and Attitude Scale on eye donation at Yenepoya pre- university college, Mangalore, India.

\section{Results :}

\section{Knowledge scores}

Many of the subjects (48\%) had good knowledge, followed by average knowledge for $44 \%$, very good knowledge for $7 \%$ and poor knowledge for $1 \%$ [Figure 1].

The mean percentage of overall level of knowledge was $57 \%$ which indicates a good level of knowledge among adolescents regarding eye donation [Table 1].

\section{Attitude scores}

Majority (72\%) of the subjects had positive attitude, followed by $(26 \%)$ of the subjects had highly positive attitude and $2 \%$ had negative attitude towards eye donation [Figure 2].

The mean percentage of overall level of attitude was $70.5 \%$ which indicates a positive attitude among adolescents towards eye donation [Table 2].

\section{Co-relation between knowledge and attitude}

There was a positive correlation between knowledge and attitude among adolescents regarding eye donation $\left(r_{(98)}=\right.$ 0.201 , table value $r_{(98)}=0.236, p<0.313$ ) [Table3]

\section{Association between knowledge scores and selected demographic variables}

There was no significant association between knowledge scores and the demographic variables.

\section{Association between attitude scores and selected demographic variables}

There is a significant association between attitude scores 
and demographic variable gender $\left(\chi_{(1)}^{2}=4.04\right.$, table value $\left.\chi_{(1)}^{2}=3.84 ; p<0.05\right)$ and no significant association with other demographic variables [Table 4].

Figure 1: Cylindrical diagram showing the Percentage distribution of subjects according to their level of knowledge

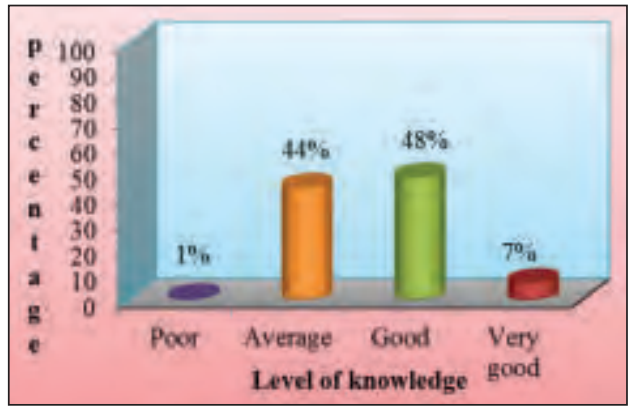

Figure 2: Bar diagram showing the distribution of subjects according to level of attitude

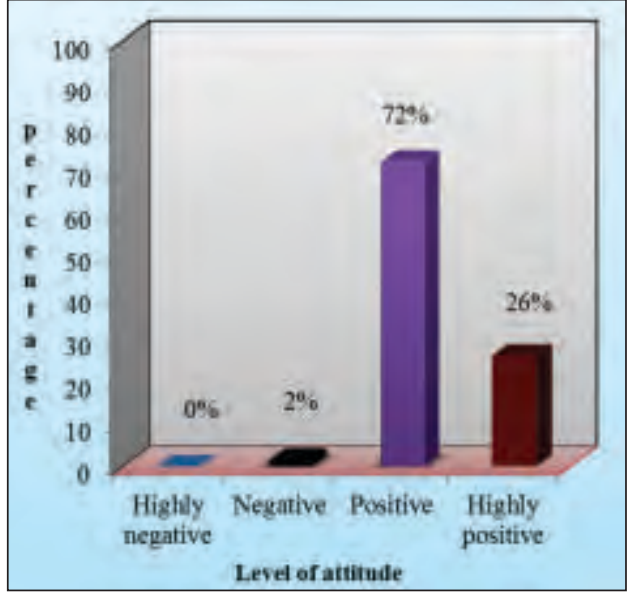

Table 1: Mean, Median, Mean percentage and Standard Deviation of knowledge scores

$\mathrm{N}=100$

\begin{tabular}{|c|c|c|c|c|c|c|}
\hline $\begin{array}{c}\text { MAX } \\
\text { POSSIBLE }\end{array}$ & $\begin{array}{c}\text { MIN } \\
\text { SCORE } \\
\text { SCORE }\end{array}$ & $\begin{array}{c}\text { MAX } \\
\text { OBTAI } \\
\text { NED }\end{array}$ & $\begin{array}{c}\text { MEARE } \\
\text { OBTAI } \\
\text { NED }\end{array}$ & MEDIAN & $\begin{array}{c}\text { MEAN } \\
\%\end{array}$ & $\begin{array}{c}\text { STAND } \\
\text { ARD } \\
\text { DEVIAT } \\
\text { ION }\end{array}$ \\
\hline 18 & 5 & 16 & 10.26 & 10 & 57 & 2.63 \\
\hline
\end{tabular}

Table 2: Mean, Median, Mean Percentage and Standard Deviation of attitude scores

$\mathrm{N}=100$

\begin{tabular}{|c|c|c|c|c|c|c|}
\hline MAX & MIN & MAX & MEAN & MEDIAN & MEAN & STAND \\
\hline POSSIBL & SCORE & SCORE & & & $\%$ & ARD \\
\hline SCORE & $\begin{array}{l}\text { OBTAI } \\
\text { NED }\end{array}$ & $\begin{array}{l}\text { OBTAI } \\
\text { NED }\end{array}$ & & & & $\begin{array}{c}\text { DEVIAT } \\
\text { ION }\end{array}$ \\
\hline 70 & 35 & 70 & 49.35 & 48 & 70.5 & 7.17 \\
\hline
\end{tabular}

Table 3: Relationship between knowledge and attitude $\quad \mathrm{N}=100$

\begin{tabular}{|l|c|c|c|c|}
\hline & MEAN & $\begin{array}{c}\text { STANDARD } \\
\text { DEVIATION }\end{array}$ & $\begin{array}{c}\text { CORRE- } \\
\text { LATION }\end{array}$ & REMARKS \\
\cline { 1 - 3 } Knowledge & 10.26 & 2.63 & 0.201 & Significant \\
\cline { 1 - 3 } Attitude & 70.5 & 7.17 & & \\
\hline
\end{tabular}

Table value $r_{(58)}=0.236, p<0.313$

Table 4: Association between attitude scores and selected demographic variables

$\mathrm{N}=100$

\begin{tabular}{|c|c|c|c|c|}
\hline \multirow{2}{*}{$\begin{array}{l}\text { Sl. } \\
\text { No. }\end{array}$} & \multirow{2}{*}{$\begin{array}{l}\text { Demographic } \\
\text { variables }\end{array}$} & \multicolumn{2}{|c|}{ Attitude scores } & \multirow{2}{*}{$\begin{array}{l}x^{2} \\
\text { (df) }\end{array}$} \\
\hline & & $\begin{array}{c}\text { Median } \\
<48\end{array}$ & $\begin{array}{c}\text { Median } \\
\geq 48\end{array}$ & \\
\hline \multicolumn{5}{|c|}{ 1. Age in years } \\
\hline & $16-18$ & 43 & 48 & $\$ 3.051$ \\
\hline & More than 18 & 7 & 2 & (1) \\
\hline \multicolumn{5}{|c|}{ 2. $\quad$ Gender } \\
\hline & Male & 18 & 9 & $* 4.042$ \\
\hline & Female & 32 & 41 & $(1)$ \\
\hline \multirow[t]{5}{*}{3.} & Religion & & & \\
\hline & Hindu & 16 & 25 & 1.622 \\
\hline & Christian & 27 & 13 & $(1)$ \\
\hline & Muslim & 7 & 12 & \\
\hline & Others & 0 & 0 & \\
\hline \multirow[t]{3}{*}{4.} & Place of residence & & & \\
\hline & Urban & 27 & 31 & 0.331 \\
\hline & Rural & 22 & 20 & $(1)$ \\
\hline \multirow[t]{4}{*}{5.} & Type of family & & & \\
\hline & Nuclear & 31 & 29 & $\$ 0.701$ \\
\hline & Joint & 15 & 19 & (1) \\
\hline & Extended & 4 & 2 & \\
\hline \multirow[t]{8}{*}{6.} & Educational status 0 & father & & \\
\hline & No formal schooling & 0 & 2 & 0.372 \\
\hline & Primary school & 7 & 4 & $(1)$ \\
\hline & High school & 10 & 10 & \\
\hline & Higher secondary & 14 & 12 & \\
\hline & Diploma & 7 & 4 & \\
\hline & Graduate & 8 & 14 & \\
\hline & Post graduate & 4 & 4 & \\
\hline \multirow[t]{8}{*}{7.} & Education status of & nother & & \\
\hline & No formal schooling & 2 & 3 & 0.444 \\
\hline & Primary school & 10 & 8 & (1) \\
\hline & High school & 15 & 7 & \\
\hline & Higher secondary & 9 & 16 & \\
\hline & Diploma & 8 & 7 & \\
\hline & Graduate & 3 & 7 & \\
\hline & Post graduate & 2 & 2 & \\
\hline \multirow[t]{6}{*}{8.} & Which of your famil & member & ve donat & their eye \\
\hline & Grand parents & 0 & 0 & $\# 0.521$ \\
\hline & Parents & 0 & 1 & $(1)$ \\
\hline & Sibling & 0 & 0 & \\
\hline & Any relative & 3 & 3 & \\
\hline & None & 47 & 46 & \\
\hline
\end{tabular}




\begin{tabular}{|c|l|c|c|c|}
\hline \multirow{2}{*}{$\begin{array}{c}\text { SI. } \\
\text { No. }\end{array}$} & Demographic & \multicolumn{2}{|c|}{ Attitude scores } & \multirow{2}{*}{$\begin{array}{c}\mathbf{2} \\
\text { variables }\end{array}$} \\
\cline { 3 - 4 } & & $\begin{array}{c}\text { Median } \\
<\mathbf{4 8}\end{array}$ & $\begin{array}{c}\text { Median } \\
\text { (df) }\end{array}$ & \\
\hline $\mathbf{9}$ & Which of your family member have pledged their eye \\
\hline & Grandparents & 0 & 0 & $\# 0.121$ \\
\hline & Parents & 0 & 3 & $(1)$ \\
\hline & Siblings & 0 & 0 & \\
\hline & Any relative & 6 & 2 & \\
\hline & None & 44 & 45 & \\
\hline $\mathbf{1 0 .}$ & Any information regarding eye donation \\
\hline & Yes & 25 & 31 & 1.461 \\
\hline & No & 25 & 19 & $(1)$ \\
\hline
\end{tabular}

Table value $\chi_{(1)}^{2}=3.84 ; p<0.05$, $\$$ chi- square Yates correction, \# Fisher exact test, *significant

\section{Discussion :}

In this study: many of the subjects (48\%) had good knowledge, followed by average knowledge for $44 \%$, very good knowledge for $7 \%$ and poor knowledge for $1 \%$. The mean percentage of overall level of knowledge was $57 \%$.

Majority (72\%) of the subjects had positive attitude, followed by $(26 \%)$ of the subjects had highly positive attitude and $2 \%$ had negative attitude towards eye donation, the mean percentage of overall level of attitude was $70.5 \%$.

The following studies support the findings of the current study: A study was conducted to analyze the degree of awareness about eye donation and corneal transplantation among 425 hospital based and rural population in Chennai. The data were collected using a structured knowledge questionnaire. The results showed that 367 (86\%) people had high awareness regarding eye donation, 135 (31.76\%) people had the wrong belief that the whole eye is transplanted, 314 (73.88\%) people knew that eyes can be pledged during life and age is not bar to eye donation. One hundred and nine $(25.65 \%)$ subjects feared that eye removal cause disfigurement of the face, 101 (23.76\%) people wrongly believed that eyes could be brought or sold. Sixty-two (14.59\%) people had misconception that diabetes mellitus was contraindication to eye donation. The study concluded that the awareness about eye donation was quite high, yet certain misconceptions need to be clarified ${ }^{12}$.
A prospective study was conducted to evaluate the response to request for eye donation from relatives of post mortem cases. The results showed that of the 159 donors identified, there were 119 (74.8\%) men, 40 (25.2\%) women and $88(74.8 \%)$ kin were aware of the concept of eye donation, but $71(44.7 \%)$ families had not heard of it before. Willingness for eye donation was seen in 66 (41.5\%), whereas 93 (58\%) families refused eye donation. The study concluded that active counseling by a motivated team can be effective even in families with no prior knowledge and low socioeconomic status to undertake eye donation from relatives of post-mortem cases $^{13}$.

In this study: There was a positive correlation between knowledge and attitude among adolescents regarding eye donation $\left(r_{(98)}=0.201\right.$, table value $\left.r_{(98)}=0.236, p<0.313\right)$.

The following study supports the findings of the current study: A correlative study was conducted to assess the knowledge and attitude towards eye donation among baccalaureate nursing students in Puduchery. Fifty nursing students were selected using convenient sampling. The data were collected using questionnaire, and analyzed using descriptive and inferential statistics. The findings of the study revealed that $90 \%$ of the B.Sc nursing students had adequate knowledge regarding eye donation and 10\% of them had moderate knowledge. More than half the respondents i.e. $52 \%$ had a moderately favorable attitude while $44 \%$ had a favorable attitude. There was a positive correlation between knowledge and attitude regarding eye donation. $(r=0.354 P<0.01)^{14}$.

In this study: there was a significant association between attitude scores and demographic variable gender $\left(x^{2}{ }_{(1)}=\right.$ 4.04 , table value $\left.\chi_{(1)}^{2}=3.84 ; p<0.05\right)$

The following study supports the findings of the current study: A study was conducted to assess the knowledge, attitude and practices of the 357 medical and surgical patients regarding eye donation in Pakistan. Systematic sampling was used and interviewed. The results showed that $59.9 \%$ of the populations were willing to donate their eyes. Knowledge of eye donation was significantly 
associated with education and socio economic statistics. Willing to donate had a significant association with gender. The study concluded that awareness of eye donation and the knowledge that eye donation can give lives was also significantly associated with willingness to donate ${ }^{15}$.

\section{Conclusion :}

- Many of the subjects (48\%) had good knowledge, followed by average knowledge for $44 \%$, very good knowledge for $7 \%$ and poor knowledge for $1 \%$.

- Majority (72\%) of the subjects had positive attitude,

\section{Reference:}

1. Richard L. Eye donation, the gift of sight of sight. Nightingale Nursing Times. 2009 Jul; 5(4):24-5.

2. Kasturi SR. Community health nursing, $3^{\text {rd }}$ ed. Chennai: K. V. M athew Publication; 2000

3. Mohan R K. Eye donation. Accessed from http://www. mohanfoundation. org. Accessed on 7 Dec 2012.

4. Sunilkumari K. Problems and coping strategies of blind children. NNT. 2009; oct5 (7):54-56.

5. Karnataka state health and family welfare society blindness control division. Electronic register form no- 11.

6. Kam weng boey. A cross validation study of nurse's attitude and commitment to organ Donation in Honk Cong. International journal of nursingstudies. 2000 July; 39(23):95-104.

7. Pawlins A. Eye-donation-some-facts-and-stats. Accessed from http:// fallofsupercomputer.blogspot. Accessed on 4 Dec 2012.

8. Barbara CL, Wilma J P, Virginia LC. M edical Surgical Nursing, A Nursing process approach. $3^{\text {rd }}$ ed. M issouri: Alison M iller publication; M osbyyear book.Inc. St. Lowis. 1993:1310-1312.

9. Biswas ], Bandyopadhyay S, Das D, M andol KK, Saha I, Ray B. A study in awareness about eye health care and eye donation among followed by $(26 \%)$ of the subjects had highly positive attitude and $2 \%$ had negative attitude towards eye donation.

- There was a positive correlation between knowledge and attitude scores among adolescents regarding eye donation $\left(r_{(98)}=0.201\right.$, table value $\left.r_{(98)}=0.236, p<0.313\right)$.

- There was a significant association between attitude scores and demographic variable gender $\left(\chi_{(1)}^{2}=4.04\right.$, table value $\left.\chi_{(1)}^{2}=3.84 ; p<0.05\right)$

secondary level students of North Kolkata, India. Indian Journal Opthalmology. $2003 \mathrm{Mar}$; 51 (1): 101-4.

10. Talbot LA. Principles and practice of nursing research. Philadelphia: Times M irror company; 1995.

11. Krishnaiah S, Kovai V, Nutheti R, Shamanna BR, Thomas R, Rao GN, et al. Awareness of eye donation in the rural population of India. Indian J Opthalmology. $2004 \mathrm{M}$ ar; 52(1):73-8.

12. Suresh K, Priyanka P, Shanmugha P. Awareness of eye donation in rural and hospital based population. Indian Journal for the Practicing Doctor. 2008; 4(6):27-30.

13. Tandon R, Verma K, Vanathi M, Pandey RM, Vajpeyee R. Factors affecting eye donation from post mortem cases in a tertiary care hospital. Cornea. 2004 Aug; 23(6):597-601.

14. Brinda P, M uthiah S, AlagarsamyS, Sethuraman S, Ram SD, Praveen KN. Awareness of eye donation in an adult population of southern India: a pilot study, Indian journal of opthalmalogy. 2003J an; 8(51):101-04.

15. Omer Ashraf, Saad Ali, Sumbul A et al. "Attitude Towards corneal Donation. A Survey in Pakistan". M edical College, Aga Khan University, Karachi, Sind, Pakistan.2005-June, International Center for Artificial Organs and transplantation. 